\title{
Evaluation of the long-term impact of the TOSTAN programme on the abandonment of FGM/C and early marriage: Results from a qualitative study in Senegal
}

\author{
Nafissatou J. Diop \\ Population Council \\ Amadou Moreau \\ Helene Benga
}

Follow this and additional works at: https://knowledgecommons.popcouncil.org/departments_sbsr-rh

Part of the Demography, Population, and Ecology Commons, Family, Life Course, and Society Commons, Gender and Sexuality Commons, International Public Health Commons, Maternal and Child Health Commons, Sociology of Culture Commons, and the Women's Health Commons How does access to this work benefit you? Let us know!

\section{Recommended Citation}

Diop, Nafissatou J., Amadou Moreau, and Helene Benga. 2008. "Evaluation of the long-term impact of the TOSTAN programme on the abandonment of FGM/C and early marriage: Results from a qualitative study in Senegal," FRONTIERS Final Report. Washington, DC: Population Council. 


\title{
Evaluation of the Long-term Impact of the TOSTAN Programme on the Abandonment of FGM/C and Early Marriage: Results from a qualitative study in Senegal
}

\author{
Population Council \\ Nafissatou J. Diop, Ph.D \\ Amadou Moreau \\ Hélène Benga
}

January 2008

This study was made possible by the generous support of the American people through the United States Agency for International Development (USAID) under the terms of Cooperative Agreement No. HRN-A00-98-00012-00 and Population Council In-house project 5804 53102. The contents are the responsibility of the FRONTIERS Program and do not necessarily reflect the views of USAID or the United States Government. 


\section{SUMMARY}

In 1998-1999, a village empowerment programme was implemented in the Thiès / Fatick and Kolda regions of Senegal by the non-governmental organization Tostan. This report is the qualitative component of an evaluation conducted at the request of UNICEF to assess the impact of this programme several years after its implementation. The overall responsibility of the evaluation was given to Macro International. The Human Development Research Centre (CRDH) implemented the quantitative component and the Population Council implemented the qualitative component, with funding from USAID through its Frontiers in Reproductive Health program.

In 1998, the Tostan program was organised around the following modules: problem solving; basic hygiene; oral rehydration therapy (ORT) and vaccination; resource and financial management; leadership; feasibility studies (income-generating / micro-credit projects); women's health (sexuality, pregnancy management); child development; democracy; and sustainable management of natural resources. The ultimate goal of the programme was to mobilise communities to hold public declarations in support of abandoning harmful traditional practices, including FGM/C and child marriage. The objectives of this evaluation were to assess the:

- Overall impact of the program implemented by Tostan on the daily life of women and men in several communities in Senegal;

- Post declaration phase of the program, in order to evaluate whether it is associated with actual abandonment of FGM/C and to estimate the magnitude and pace of abandonment;

- Abandonment of child marriage as it is associated with FGM/C.

The methodology used to conduct the qualitative component of the evaluation was based on conversations and observations in two categories of villages: type A villages, which participated in the program and held a public declaration abandoning FGM/C; and type B villages, which had only attended a public declaration, without prior participation in the program. The Population Council conducted interviews in 12 villages, ten type A and two type B villages; this was because all other villages originally identified as type B participated in the program later.

A total of 150 individual interviews were conducted among the following groups: women who had participated in the program; women from both types of villages who had not participated in the program; facilitators who had taught the program; and leaders and other resource persons in these localities. Inclusion of input from male and female leaders could result in a bias with respect to the perceptions, effects, and knowledge acquired through the program.

The program was introduced in the villages in several participatory phases: dialogue, identification and selection of participants, and implementation of the program itself. Tostan set a number of criteria for village selection, having to do primarily with the village leaders' willingness to feed and accommodate a program facilitator, prepare lists of program recipients, and construct a classroom facility. Some informants mentioned the abandonment of FGM/C as a condition for being accepted within the program but this has been reported as marginal. In 
general, the communities themselves contributed significantly to the introduction and implementation of the program in the villages.

After delivery of the education program, numerous changes took place in the villages. Informants reported that the program improved knowledge of rights and responsibilities among both participating and non-participating women, particularly with respect to the place and role of women in the community.

The organization of public declarations evolved significantly over time, even as early as 1996 2000. The idea of a public declaration was initially suggested by Tostan and acted upon later by the women of Malicounda, the first village where this process took place. However, changes occurred later in the process of organizing the public declarations. In Medina Cheriff, another village that participated in a subsequent program, several other parties played an active role in the public declaration and mobilization efforts to abandon FGM/C. This change was guided by recognition that the implementation of the decisions announced at the public declaration required the involvement of several social groups in the villages. Information from the interviews indicates that collective determination on the part of the communities to honour these commitments, along with the support of leaders, committees and women, influenced how effective the declaration would ultimately be. However, type B villages were not truly associated with the public declarations. Some people in these villages simply heard that festivities were being held in a neighbouring village, so a few representatives decided to attend. They learned of the public declaration to abandon FGM/C only after their arrival.

Although the dangers of early marriage were not clearly grasped in all the villages, those villages that received the full education program had a greater awareness of the dangers of FGM/C. This prompted the communities to call for a public declaration to abandon these practices, which was perceived as the ultimate objective of the Tostan programme. The information gathered from the communities indicates that many did end the practice following a public declaration, although residual resistance does exist in some villages. Some respondents indicated that early marriages are less frequent now, but the factors influencing this decline cannot be attributed solely to Tostan.

Village committees were formed in the villages prior to implementing the educational programme. In some areas, public declarations seem to have played a role in bolstering these groups' efforts to monitor the enforcement of decisions taken at the declarations. However, at the time of the evaluation seven years later, these groups / committees no longer exist. The lack of systematic follow-up and basic infrastructure in the villages is preventing the populations from making full use of their new capacities and is a significant barrier hindering their ability to apply the knowledge gained from the program. 


\section{TABLE OF CONTENTS}

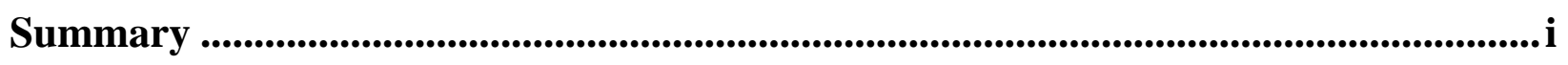

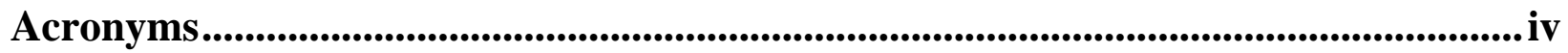

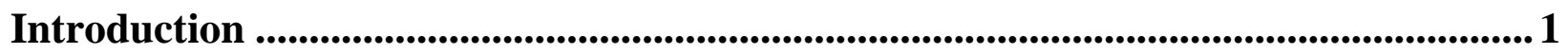

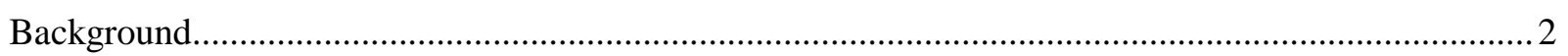

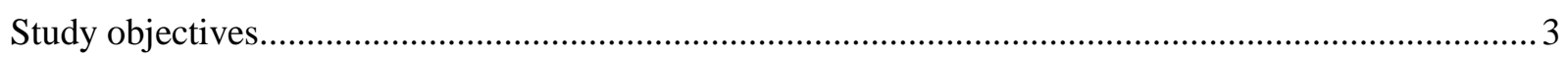

Methodology .................................................................................................................................................... 4

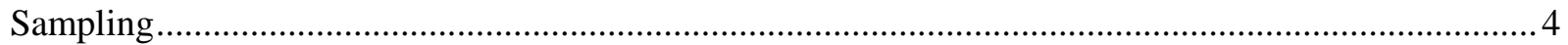

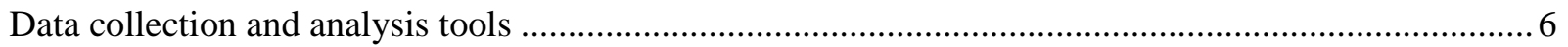

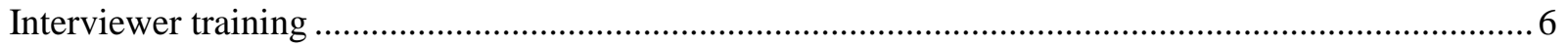

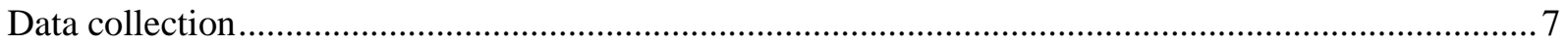

Information entering, processing and analysis ………………………………………………...

TOSTAN programme design and introduction....................................................................... 7

Introducing the programme to the villages.......................................................................................

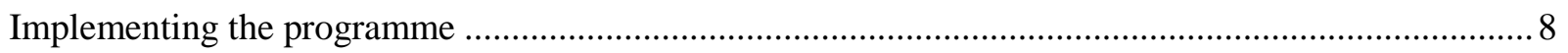

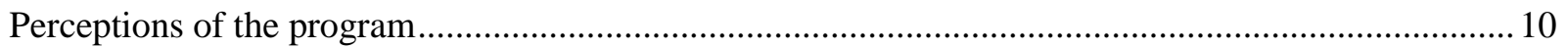

Possible Effects....................................................................................................................................... 11

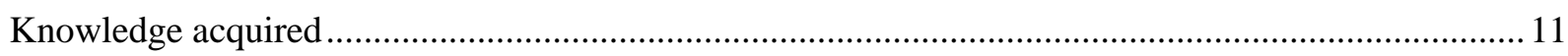

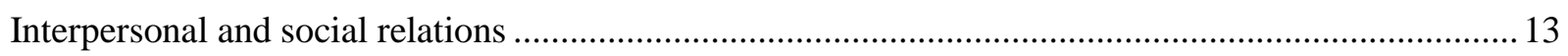

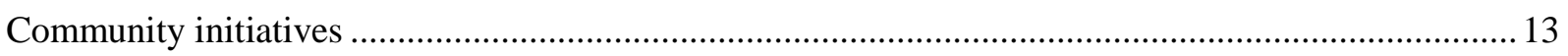

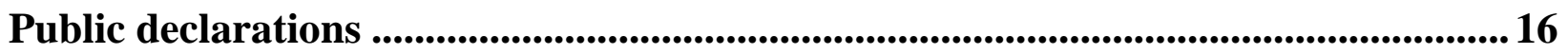

Initiation of public declarations and adherence to the mobilisation process ......................................... 16

Participation in public declarations by villages that did not receive the programme ............................. 18

Designation of village representatives to attend the declaration ......................................................... 19

Measures adopted in conjunction with the public declaration.............................................................22

Enforcement of measures and community monitoring ....................................................................2

Effect on early marriage ..........................................................................................................2 23

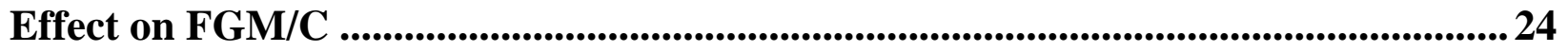

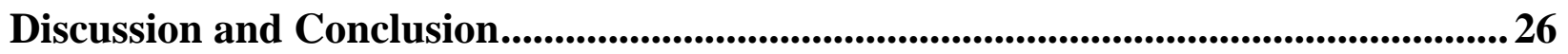

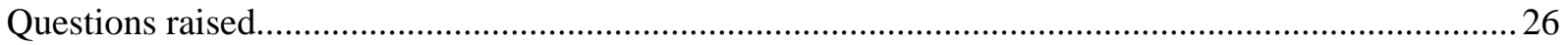

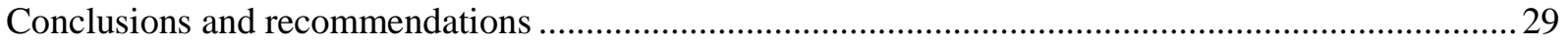

References............................................................................................................................................... 31 


$\begin{array}{ll}\text { ACRONYMS } \\ \text { DHS } & \text { Demographic and Health Survey } \\ \text { FGM/C } & \text { Female Genital Mutilation / Cutting } \\ \text { GAW } & \text { Group for the Advancement of Women } \\ \text { GAYP } & \text { Group for the Advancement of Young People } \\ \text { CRDH } & \text { Human Development Research Centre } \\ \text { MWRA } & \text { Married Women of Reproductive Age } \\ \text { ORT } & \text { Oral Rehydration Therapy } \\ \text { SCA } & \text { Sports and Cultural Association } \\ \text { TBA } & \text { Traditional Birth Attendant }\end{array}$




\section{INTRODUCTION}

Tostan focuses on two types of activities: an education program to educate a group of women in a village; and a social mobilisation strategy that, in some cases, leads to a public declaration. Tostan promotes social change by building learners' capacities to become the agents of positive change in their communities. The program targets mainly adult women, closely involving them in a learning process, the ultimate aim of which is the adoption of healthy behaviours. Tostan's education program in 1998 - 1999 covered the following topics:

- Problem-solving

- Basic hygiene

- Oral rehydration therapy (ORT) and vaccination

- Resource and financial management

- Leadership

- Feasibility studies (income-generating / micro-credit projects)

- Women's health (sexuality, pregnancy management)

- Child development

- Democracy

- Sustainable management of natural resources.

$\mathrm{FGM} / \mathrm{C}$ is only one session within this curriculum. The education programme is taught through establishing community classes in villages, in which about 30 women attend sessions three times a week over a period of one to two years; participation in classes is voluntary. A facilitator is recruited by Tostan to teach the education program in the local language. The leaders of the village convene a meeting of all the villagers and inform the community about the programme that Tostan would like to implement. Those who want to participate are invited to give their name to the facilitator. Women of reproductive age were the primary targets of the program in 1996-1998. However the Tostan curriculum evolved over time, and today the programme is set up differently to include men. This knowledge acquisition and awareness-raising process is only one aspect of Tostan's program; the other major component is to encourage public declarations for the abandonment of harmful practices and adoption of healthy behaviours.

In 1996, Tostan began suggesting that public declarations be organised as a way for communities to publicly announce the abandonment of traditional practices, such as FGM/C and early marriage. Almost all of the villages that participated in the programme held a public declaration expressing their intention to abandon these practices. The social mobilisation process surrounding these declarations also involved neighbouring villages that had not received the Tostan program.

In Senegal, the national prevalence of FGM/C of approximately $28 \%$ masks wide disparities among ethnic groups. According to recent data published in the 2005 Demographic and Health Survey (DHS), the prevalence of FGM/C varies according to ethnic group, being $78 \%$ among the Soninkes, 74\% among Mandingos, 62\% among Fulani and 60\% among Diolas. These are the populations that were targeted by Tostan. To measure the long-term impact of this programme, information must be gathered on actual changes with respect to FGM/C and early marriage. The 
purpose of this evaluation is to provide a better understanding of changes in the communities over the long-term. Therefore a period of at least six years was chosen.

This evaluation is the result of a collaborative effort by several institutions: UNICEF, Macro International, the Population Council, the Human Development Research Centre (CRDH) and Tostan. Macro International coordinated the evaluation with financing from UNICEF and the assistance of the Population Council for the qualitative component and the CRDH for the quantitative component. USAID provided financing and human resources for the qualitative component through the Frontiers in Reproductive Health program. The Population Council worked with UNICEF representatives in Senegal to involve government partners and NGOs.

\section{Background}

This study covers the regions of Kolda, Thiès and Fatick, located in southern and western Senegal, respectively. Kolda's annual population growth is high, due to a high fertility rate (seven children per woman) and low contraceptive prevalence rate (3\%). Early marriage is the norm among women (mean age of 16 years). This region is populated primarily by the Fulani/Peul and secondarily by the Mandingo.

The Kolda Region has a poorly developed health infrastructure and lacks qualified personnel, leading to inadequate provision of medical services, especially to women and children. Kolda has one doctor for every 86,117 residents and one state nurse and one registered midwife for every 13,205 married women of reproductive age (MWRA); whereas for the country as a whole, the ratios are one doctor for every 12,700 residents, one state nurse for every 4,300 residents and one midwife for every 3,283 MWRA. The maternal mortality rate is the highest in Senegal, with 1,225 deaths per 100,000 women. The illiteracy rate is especially high here, with $90 \%$ of the adult population unable to read, a factor that severely limits their access to information and development activities in an area already lacking in media exposure.

In the Fatick region, development indicators are also low. Despite an existing health infrastructure, Fatick has only one doctor for every 49,407 residents, one nurse for every 7,382 residents and one midwife for every 8,690 MWRA. The health infrastructure coverage rate is one health post for every 9,175 residents and one health centre for every 107,050 residents. Fatick's illiteracy rate is also high, at approximately 60\%. It is even higher among women, especially in rural areas. In both regions, economic migrations have resulted in a blending of ethnic groups.

The Thiès region is home to $13 \%$ of the nation's population and accounts for $70 \%$ of the nation's fish production, ranking it second after Dakar. The two regions' ethnic groups include Wolof, Serere, Pulaar, Mandingo, Bambara and Diola. Thiès has an illiteracy rate of $60 \%$. Health care coverage is one health centre for every 33,189 residents. Thiès, as in Fatick, has an economy dominated by fishing, agriculture (market farming, fruit production) and livestock production. The region suffers greatly from an irregular water supply. The scarcity of this natural resource severely impacts the populations' ability to meet their vital needs. Wells and boreholes are few in 
number and are poorly distributed as in Fatick, for example ${ }^{1}$, where inhabitants must travel great distances for water: in fact, $46 \%$ of villages who have access to water must still travel more than $2 \mathrm{~km}$ to a hydraulic well or borehole and only $50 \%$ of the population in this region has access to drinking water at all. Overall, the size of the population in each village varies a lot. Several of them have small populations (less than 20 households). The mean number is 100 households per village according to the census (RGPH 2002).

\section{Study objectives}

The study had two overall objectives:

- To assess the impact of the Tostan programme on daily life in the villages and on their rates of FGM/C and early marriage, according to defined indicators.

- To assess the impact of village participation in public declarations on the incidence of FGM/C and early marriage.

Other objectives specific to the qualitative component of the evaluation were to:

1. Determine whether the programme helped the villages form organised social groups for the betterment of the community;

2. Describe the composition of these groups, the tasks they perform and recent activities organised by them for the betterment of the community;

3. Identify those who play leadership or specialist roles in the village with respect to FGM/C or marriage;

4. Gain an understanding of the perspectives and thought processes of village leaders concerning the effects of the Tostan programme in their respective villages;

5. Identify changes in practices that may have resulted from Tostan's activities;

6. Identify those in the village who had helped organise a public declaration;

7. Clarify how participation of village residents in the public declaration was organised;

8. Describe what discussions and presentations took place in village communities after the public declaration;

9. Determine a model for monitoring the abandonment of FGM/C and early marriage following the public declaration;

10. Define the positions of those who participated in the public declaration on the importance of this event in the life of the village.

\footnotetext{
${ }^{1}$ Economic and Social Situation in the Fatick Region, Republic of Senegal, Ministry of the Economy and Finance, Directorate of Forecasting and Statistics, Regional Service of Fatick, August 2005.
} 


\section{METHODOLOGY}

The qualitative evaluation was based on an analysis of responses to the following research questions:

1. What lasting effects remain from village participation in the Tostan programme?

2. In villages that received the Tostan programme, how do the lives of women who participated in the programme differ from those who did not?

3. How was participation of villages in a public declaration organised after the education programme?

4. How did villages that had not received the Tostan programme come to participate in a public declaration?

5. What efforts were made after the public declaration to monitor changes in the practice of FGM/C and early marriage?

\section{Sampling}

\section{Villages included in the study}

The evaluation was conducted in a group of villages in which Tostan was active between 1996 and 2000 in the regions of Thiès, Fatick and Kolda. For this qualitative assessment, villages were selected on the basis of the villages sampled for the quantitative survey conducted by the CRDH (See quantitative report for detail information) ${ }^{2}$. Sixteen villages were initially targeted for the survey, divided into two sub-groups, type A and type B:

- Type A villages were those that had received the Tostan programme and made a public declaration during the study reference period;

- Type B villages were those that had participated in a public declaration to abandon FGM/C during the same period, without having previously received the Tostan programme.

In the Thiès and Fatick regions, a problem arose with village selection. There was an absence of type B villages in this region due to the fact that all of the villages had both received the Tostan programme and participated in a public declaration to abandon FGM/C, as many villages participated in a phase of the education programmes subsequent to the declarations. For this reason, only two type B villages were surveyed for the evaluation in this region. In the Kolda region, it was discovered that some of the villages selected as type B had actually participated in the Tostan programme subsequent to the study period. This was true of two villages identified as type A that had received the Tostan programme after attending a public declaration to abandon FGM/C in Medina Cherif.

Thus in all, twelve villages were included in the qualitative study: eight in Kolda (six type A and two type B), and four in Thiès/Fatick (all type A). In total there were 10 type A villages and 2

\footnotetext{
${ }^{2} \mathrm{CRDH}$, Macro International and Unicef. 2007. Evaluation à long terme de l'impact du programme de Tostan. Enquête quantitative.
} 
type B. Adherence to the sample of villages included in the quantitative survey prevented the qualitative research team from identifying other type B villages to achieve a balance of respondents.

\section{Target populations}

Selection of the target population in the study villages was based firstly on identification of resource persons able to answer questions that could be used to develop a village profile. Next, these resource persons had to be able to identify other community members who met the following criteria: women who had participated in the program; women who had not participated in the program; male, female and youth leaders; and others who had been present during this period, such as health or education administrators.

To facilitate selection of interviewees, the research team for each village prepared lists of key informants. Tostan staff in Thiès provided lists of facilitators who had implemented the program at that time in each village. An effort to find them in areas where they were currently working was undertaken and all facilitators were interviewed, except one (the facilitator for Keur Simbara was not in the country at the time of the survey).

Leaders to be interviewed were selected mainly from these lists. These included the village chief or his deputy, the imam (religious leader), the principal of the village school, group / committee presidents, etc. On average, three people from this category were interviewed in each village.

The other target group consisted of women, who made up the majority of the interview sample. The research team was assisted in identifying the women to be interviewed by the president of the women's group who was normally the most involved with village life and organisation. Of the group of women still living in the village, a selection of women was made to represent different age ranges. At least six women were surveyed in each village, three women who had participated in the programme and three who had not. Non-participating women were selected according to the role and tasks they performed in the community after the village had participated in the programme and made a public declaration. These women also had to have been present in the village while the programme was being implemented. An additional criterion was their location in the village, which was divided during data collection into different geographical areas to facilitate the selection of this sub-group of women.

It should be noted that the inclusion of male and female leaders may result in bias, because such leaders are generally the main target of the Tostan program and are therefore more inclined to have positive perceptions of it. We recognize that in our discussions of programme perceptions, knowledge acquired, and programme effects, the image presented may reflect a positive bias.

In addition, informal interviews were conducted to gather information on how the village organises itself, the actions of committees and the role of women, and the situation with respect to FGM/C and early marriage. These interviews included members of various social groups such as traditional birth attendants (TBA) and male head nurses, principals of village schools, leaders of sports and cultural associations (ASC), literacy instructors, and dahira leaders. 
Table 1: Distribution of target population by village type

\begin{tabular}{|c|c|c|c|c|c|}
\hline \multirow{2}{*}{$\begin{array}{c}\text { Village } \\
\text { type }\end{array}$} & $\begin{array}{c}\text { Participating } \\
\text { women }\end{array}$ & $\begin{array}{c}\text { Non-participating } \\
\text { women }\end{array}$ & Leaders & Facilitators & $\begin{array}{c}\text { Other information } \\
\text { providers }\end{array}$ \\
\hline A & 28 & 33 & 36 & 7 & 24 \\
\hline B & -- & 12 & 8 & -- & 2 \\
\hline Total & $\mathbf{2 8}$ & $\mathbf{4 5}$ & $\mathbf{4 4}$ & $\mathbf{7}$ & $\mathbf{2 6}$ \\
\hline
\end{tabular}

\section{Data collection and analysis tools}

The materials used to collect and analyse data were prepared in two phases. Four types of interview guides were prepared first:

- A guide for developing village profiles

- A guide for interviewing women (participating and non participating women in both types of villages)

- A guide for interviewing village leaders

- A guide for interviewing Tostan programme facilitators.

The profile guide was initially tested in a few villages around Thiès. After this pilot phase, the profile guide was finalised and the other interview guides were developed. After data collected was completed, five data processing "booklets" were prepared to guide analysis by the research team:

- A booklet for identifying the different interviewees

- A booklet for leaders

- A booklet for women

- A booklet for facilitators

- A booklet for other information providers interviewed, such as literacy instructors, TBAs, and male head nurses.

\section{Interviewer training}

Training sessions were held in February 2006, assisted by the senior researcher of Macro International. Interviewers were trained in the process and objectives of the evaluation, and were presented a summary of the Tostan programme content. The various parts of the guides to be used for gathering information were discussed in detail and translated, with the help of the Tostan team, into Wolof, Mandingo and Pulaar to assist the data collection team in 
communicating with the target populations. Data collectors included both men and women, and were chosen in the capital city from within the Council's pool of experienced field collectors.

An additional training stage was held after the data was collected. At this training, members of the collection team learned how to use the NUDIST software programme and to process the data collected.

\section{Data collection}

Data were collected in several stages in February and March 2006, through interviews conducted in the 12 study villages. Type A village participants were interviewed first, in order to gain a better idea of the extent of their interaction with type B villages. This strategy also made it possible to anticipate judgments on the part of type B villages that might skew the data collection process. Participants were identified with the assistance of resource persons and approached for informed consent. Interviews were conducted in their homes; all interviews were taped after obtaining the consent of the person.

\section{Information entering, processing and analysis}

The members of the research team who transcribed and entered the information also participated in its processing. Data were processed using NUDIST software twice or even three times for each interview to ensure standardisation and quality control. Data were submitted to a progressive and cross-sectional analysis to track changes in the villages, starting with programme introduction and implementation, through the process of community mobilisation around a public declaration to abandon FGM/C, and on to programme impact.

\section{TOSTAN PROGRAMME DESIGN AND INTRODUCTION}

\section{Introducing the programme to the villages}

Introduction of the Tostan programme came about as a result of a meeting between Tostan and UNICEF, two collaborative institutions sharing a common interest in improving the quality of life in this region. UNICEF officials had initially become interested in Tostan through its activities in the Thiès region, and were seeking a way to build on this experience and reproduce it in Kolda.

The programme was introduced to the villages in several phases: dialogue, identification and selection of participants, and program implementation. Tostan used a participatory approach to select villages that might benefit from the program, sending staff from the area to discuss the its various aspects with the populations prior to introducing it. This is how most villages came to join the programme, although a few requested the programme directly from Tostan after observing changes taking place in other areas in which the programme was operating. 
Matrimonial alliances also played a part in programme introduction. This was the case in Soudiane, for example, where the sister of the women's group president married someone from Fadiaale, a village that was participating in the programme. On moving to her husband's home, she had one thing in mind: "Her role was to attend all Tostan events and report back to us everything that was said." (Dahira leader, individual interview, married, age 45.) Soudiane subsequently requested the programme for itself, based on the impressions this sister shared and her desire for Soudiane to benefit from it. "When she saw how the men and women of the village mobilised around certain events, she worked to get the program for Soudiane. She did this because she realised that Tostan's activities and objectives were compatible with what we were doing in the village. After that Tostan came and gave us a letter that made us very happy."

However, Tostan set a number of criteria for village selection, primarily concerning the village's willingness to feed and shelter a facilitator, prepare lists of program recipients, and construct a classroom facility. Some respondents also mentioned abandonment of FGM/C as a condition for selection. According to one facilitator, "Yes, they are asked if they will agree to abandon $F G M / C$. If they don't agree, the programme is offered to another village. Once they accept, we begin the awareness-raising process preceding literacy." Not everyone mentioned this as a criterion, but all agreed that Tostan required the village to feed and shelter the facilitator. This, in fact, summed up the participatory approach for one facilitator: "Yes, there were criteria. They asked the village, first, 'will people attend the class?' Second, 'once you have learners, will you provide food and a bed for the facilitator who comes here, and a hut?' ... Those were the conditions!" (Facilitator, farmer, married.)

In conclusion, there appears to have been two models for programme introduction, one in which Tostan approached the village and began a series of negotiations, and one in which the people themselves requested the programme after hearing favourable things about it or having someone knowledgeable in the program migrate to the village through marriage.

Participation in setting up the classroom and providing food and lodging for the facilitator was a difficult condition to meet for the villages, which are often very poor. This explains the lengthy negotiation period, sometimes about six months. For a few villages that received the programme subsequent to the initial round, like Diabougou, abandonment of FGM/C, known to be a crucial element of the programme, was the main stumbling block to leaders' acceptance. In the end, the programme's benefits were the deciding factor. Another determining factor was the persistence of Tostan staff and their ability to employ different negotiating strategies by which the "understood" condition of abandoning FGM/C entered in only at a later stage.

\section{Implementing the programme}

The communities themselves generally contributed a great deal to programme introduction and implementation. This is especially evident in the creation of the workspace known as the classroom, be it no more than a tourdou ${ }^{3}$ set up under the tabaki tree, or a straw hut in relatively good condition able to protect participants against inclement weather.

The classroom was created through a participatory process involving various parties. Tostan provided the educational materials and the village provided the classroom. " ... We villagers

\footnotetext{
${ }^{3}$ Non-enclosed space in the open air.
} 
built the classroom, but Tostan provided all the materials, even notebooks, pens, pencils, etc. But the villagers have to choose the workspace. It's a form of financing. Tostan and the village each contribute their share." (Youth group president, farmer, married.)

Decision-making in the community was generally shared, but often according to a certain hierarchy. For example, the village chief not only authorised the creation of the classroom, but also had sole decision-making power over its location. The village chief considered this to be his decision, not Tostan's. "Oh, no, it's not up to Tostan! It's up to the village chief. Tostan can't just choose any location it wants; that's the village chief's prerogative." These remarks may reflect a certain concern with maintaining authority; however, they also illustrate the role of leaders in collective decision-making, as expressed by one school principal: "We are in a land where nothing gets done without the approval of the important people, who hold traditional decision-making power."

Villagers also worked collectively to implement the program: "Everyone worked as one and put themselves out to help Tostan so that there would be no difficulty with the courses and no problems among the participants." (Village chief, farmer, married, age 56.)

There were, of course, numerous setbacks, but "the overall view is that the entire community worked together to make sure it would go smoothly. Even the important people in the village helped out, the same as the village leaders. The village chief was constantly involved so that the program would not run into any difficulties," a school principal told us.

However, this widespread enthusiasm for accepting and setting up the programme did not carry over to class attendance. The perception was that the programme's usefulness had to be weighed against the obligations of day-to-day survival, a case some made to justify irregular attendance. For many women, domestic duties were paramount and justified missing classes. As one woman in Medina Cherif put it: "Yes, everyone who signed up participated in the training. But not everyone finished the programme because some dropped out and some were absent from time to time. This was because some didn't take it very seriously. They claimed they didn't see the importance of literacy for meeting their concrete daily needs. Others justified their absence by saying their duties at home took up all their time. Sometimes they had to leave the class so they could rest or perform certain tasks." (Participating woman, women's group member).

Still, a motivated minority of recipients were determined to take the entire programme. These participants were willing to acquire knowledge even if they believed it might not help them to get a job later. These women expressed a feeling of satisfaction. "I planned my work so I could include the training in my daily schedule. It was a challenge I set myself. I wanted to take this training even if I would not be able to use it to get a job. My goal was to acquire knowledge so I could take better care of my family, my children, and my home in general." (Participating woman).

In conclusion, most village communities contributed a great deal to programme introduction. Communities were motivated by the "novelty" aspect. Each party contributed its share. However, once class began, enthusiasm waned somewhat and students were absent or even dropped out. Household obligations, the lack of economic benefit and the demands of economic 
survival discouraged some from attending classes regularly. But very motivated women continued to participate with enthusiasm.

It should be noted that two villages in Kolda encountered difficulties in introducing the programme. In one of the villages this was due to longstanding animosities harboured by the village chief against another village. In the other village it was due to the machinations of a particular leader. However, the first village ultimately received the full program, despite the reticence of the village chief.

\section{Perceptions of the program}

Most villagers expressed positive perceptions of the programme. Recipients spoke of a feeling of satisfaction concerning the program's "usefulness," described in terms of "closer community ties" and "better lives." This was expressed in different ways in the villages: "Everyone liked the programme because it taught us to read and write in our own language and gave us other knowledge." (Women's group president, age 45.) Another woman stated that, “... this class was very useful to us. We don't have any sanitation or health problems now, thanks to the Tostan class." (Vice president, group for the advancement of women.)

However, reservations were also expressed, relating in particular to the lack of basic health and social infrastructures, and difficulties meeting basic needs. For some, Tostan had done nothing to help them address some of their most vital issues. One village chief mentioned the "limits" of the programme, which did not address the village's most pressing needs: " ... They [Tostan] claimed they would solve our problems with their programme, but they didn't solve a thing! If your child is sick here, you are the one who cares for it, not Tostan. If your wife falls ill, it is you and you alone who take care of her, not Tostan. So how can I say the Tostan programme solved our problems? They didn't provide a single health post or storage cache. We cannot say that Tostan helped us solve our problems...." Nevertheless, the interviewee recognised the need "to hold a class to educate people," which he considered the only aspect of the program that was "beneficial to village residents."

The lack of follow-up on the part of Tostan was also mentioned. One village chief said: "They [Tostan] taught their programme here for two years, then they left the way they came! They never came back here again." Village participation in setting up committees was also viewed as a heavy burden, an effort not always easy to make by these populations. "... They always told us 'bring us this, bring us that...' but apart from the class, we didn't get anything in return. Bring us this, bring us that, and in return you get nothing - is that normal? And they are in charge! Tostan is the boss! If the boss comes and finds poor "baa-doole'"[underprivileged people] and asks them for things instead of helping them, what do you call that? We are "baa-doole.." And if a company [NGO] comes to see us it should be to help us." (Village chief.)

It should be noted that these feelings were not widespread and spring for the most part from the lack of infrastructure and destitution faced by these villages. Overall, the populations appreciated the programme: "The Tostan programme brought us only advantages because it is through this programme that we became aware of the importance of sending children to school so they can learn about hygiene." (Non participating woman / women's group member, age 60.) 
In conclusion, the programme appears to have been well perceived by most villages. All of the effects mentioned by the populations were positive: greater control over collective hygiene, women's health, and girls' education; assumption of greater leadership roles; and the ability to manage a budget. No village mentioned any negative repercussions from the programme. However, the ability to apply the new knowledge was limited by a lack of infrastructure and the problem of poverty that does not permit villagers to build sanitation, access to water, to health infrastructure or schools. The programme created expectations of greater well-being and access to development structures. And although the difficulties mentioned were present everywhere, only one village informant expressed resentment toward Tostan. All of the other villages understood that the NGO had given them what it could and that it was probably up to them, the community, to find a way to build or demand better social infrastructures from the government.

\section{POSSIBLE EFFECTS}

In assessing the changes that took place after the programme was implemented, the analysis focused foremost on knowledge acquired during programme implementation and the subsequent application of this knowledge in the villages. Input concerning changes was gathered both from women who had participated in the programme and women who lived in the village but had not participated in the programme. We asked questions concerning the type of information they received from Tostan, access to medical services, village sanitation, and other benefits of the programme.

\section{Knowledge acquired}

Knowledge acquired relates essentially to aspects of daily life such as, and in particular, set setal (hygiene), the benefits of jarum xetalli (ORT), and mathematics, all of which strongly impact on behavioural changes. "We can now say that Tostan taught us a lot of things and if anyone tells you otherwise, he is dreaming! Tostan taught us how to maintain hygiene and keep our children, our home and ourselves clean, and also about the hygiene and cleanliness of our food. They also taught us how to live in harmony with our husbands, how to treat others, and the relationship we should have with our neighbours in the village and beyond. We now know what to do when our child is sick, how to care for him, etc. Plus we now know not only how to read and write but how to perform calculations in our national language, which is Peul ..." (Participating woman, age 40.)

Other knowledge acquired relates to general and reproductive health, an area that has become accessible to women in these regions. The data show the benefits they gained from the programme in terms such as these, expressed by a non participating woman: "With respect to motherhood, for example, the knowledge I acquired from the Tostan programme is extremely important to me. In the past, we didn't think prenatal visits were important." (Non participating woman, farmer, married, age 45.) 
Women are now able to track their pregnancy cycles, if they wish, thanks to the lessons of the Tostan programme, a fact related by this participating woman in Malicounda: "Now I understand better everything having to do with my health. I found out how long pregnancy lasts. Before I really wasn't sure about it. When people said 280 days, I often wondered if it was true, but in module 7, I found out it was."

Changes resulting from the programme are also apparent in women's awareness of their role in the community. One of the effects of the Tostan programme seems to have been a revision in women's status. Women now seem convinced that they can hold positions formerly held only by men. This was expressed by a participating woman in Goundaga: "Yes, we know now that women must help decide and orient things, take part in the country's important socio-economic development decisions along with the men. Now we are convinced that women can do anything men can do, sometimes better, because we have abilities and aptitudes that should be taken advantage of. Why not a woman village chief?"

The programme was also said to have promoted a "culture of hygiene" in the villages. Since the programme, villagers have placed primary importance on washing, as expressed by this participating woman: " ... Thanks to them we learned a lot about a number of things: market gardening, literacy, set setal, children's health... It changed us because we were not taking care of our homes or our children. We did not have time to wash because we were always in the bush. But ever since Tostan came to our village, we have seen big changes; everything we didn't know before, Tostan taught us."

The knowledge acquired with respect to basic mathematics has also proven to be a major asset, especially for women engaged in income-generating activities. A participating woman from Malicounda shared her experience: "... I am really good at that [laughter]. But if someone owes me money now, even if I can't write down the whole name, I can write the first few letters, and I can write the amount. And when I go to buy merchandise, I can write down everything they give me."

Such comments were to be expected from participating women, who numbered 15- 25 per village, and in fact we gathered many examples. However, knowledge was acquired not only by participating women. Examples were found of women who had benefited from the knowledge without having received the programme, as illustrated by this woman from Sare Waly: "Now even prenatal visits and vaccination of children are taking place in this village, unlike the situation before the arrival of Tostan, when women didn't think these issues were very important. We also know how to fight the spread of malaria." Such remarks reflect the pervasive impact of the social communication component of the Tostan initiative, and demonstrate fulfilment of the objectives of Ndeye Dikké (Adopt a Friend), whereby the knowledge acquired in class is shared with the entire community.

However, in Saré Demba Modou, a village that had encountered difficulties, regret was expressed by a participating woman over interruption of the program: "In the village, the training didn't last because we only met a few times and then the training stopped, I don't know why. Frankly, to tell the truth in the name of God because I am a believer, we didn't acquire any knowledge in this training. I can't say that I mastered a single point or module of this training. In reality we didn't acquire any knowledge. Today no one can tell you that they learned math or 
how to read or write with this training which, in reality, didn't last long enough to have the intended effect." However, another woman said the opposite: “... What they taught us was to foster peace, solidarity and unity forever."

\section{Interpersonal and social relations}

One of the programme's objectives is to improve marital relations. Several women interviewed emphasised better communication with their husbands and less quarrelling in situations that had previously been marked by frequent domestic violence, according to them. A few women mentioned improvements in this regard. "... In the past, women were beaten all the time by their husbands, even for little things, and they were always in the wrong. All that has changed. Now women talk and joke with their husbands and that didn't exist before." (Women's group president). This revolution in marital relations was confirmed by comments of a participating woman in Keur Simbara: "There were times, before Tostan came to this village, that there were difficulties between husbands and wives. But when Tostan arrived, they showed us the right path to follow. They taught us that when you are in a house with your husband, when something happens to you, you shouldn't hide it from him." (Participating woman, married, age 47.)

Thus, the results indicate improved gender relations in some cases. The data also show improvements in women's image and role, with women seeing themselves as capable of taking part in the making and enforcement of decisions in their communities. A participating woman from Medina Cherif told us the following in this regard: "Relations have changed between men and women, because now many of the village decisions are being made by women. We are participating in an important way in the social and economic development of this area." (Participating woman, farmer and traditional birth attendant (TBA), married, age 40.)

The Tostan programme also appears to have fostered positive changes in social relations. This is illustrated by changes in inter-ethnic relationships in the villages, expressed in the following comments: “... They have maintained their relationships even with non participating women, because at first, before the training, the Peuls and the Mandingos did not get along very well. After the Tostan training we started spending time together. The Peuls attend all the Mandingo ceremonies and vice versa. We can say that this programme brought about understanding in the village." (Non participating woman, married, age 39.) Thus the villages appear to enjoy greater social harmony.

\section{Community initiatives}

Various initiatives were taken in the villages in conjunction with the Tostan programme, both during and after its implementation. Tostan appears to have contributed to the creation of coordinating bodies in the villages, commonly known as "committees," whose purposes vary according to community interests and programme components. In many villages, these committees were created after programme implementation. However, for populations seeking development resources, these were not considered an effective collective action tool. Nonetheless, their existence in the villages "is very useful because even if 'addani kaaliss, addi 
ganndal' [even if it doesn't bring us money, it brings us knowledge]. " (Non participating woman, farmer, married, age 45.)

Various actions were taken by the women to directly apply the knowledge gained. These focused mainly on the issues covered by the programme; for example, regular cleaning of certain village areas requiring a collective investment, as described by this participating woman from Goundaga: “... We perform these set-setal activities whenever we need to in order to keep the village and its surrounding areas clean." Additional actions included "awareness talks about reproductive health, cleanliness and hygiene, to make the people aware of these important aspects of our daily lives." (Participating woman, women's group treasurer, married, age 30.)

It should be noted that in some villages these activities already existed, but the programme served to reinforce them. According to this participating woman from Malicounda: "There are things here that existed before Tostan, like the dispensary. ... I can say that it made us bolder, because before Tostan came, everything I just mentioned was already here in the village. We held meetings and exchanged ideas. We had health awareness talks. Tostan just gave us the determination to build on what we were already doing." (Participating woman, instructor, married, age 44.)

Other initiatives focused on developing small income-generating activities to improve living conditions in the villages. A non participating woman from Keur Simbara shared the following concerning the management capacities the programme developed in participants: "... Before, the women had nothing; they had only what their husbands gave them. Now when they are given money, they buy merchandise to re-sell it. When they do well, they buy chairs, armoires, sheets, curtains... everything. So you see how important these activities are." (Non participating woman, TBA, widow, age 70.)

A few initiatives focused on school attendance, particularly for girls, as a result not only of Tostan but also of other types of development programmes: "For parents, it was not important to send girls to school. But since the declaration, it has become essential. Also, a car drives around the village around the beginning of each new year to tell parents it is time to register and they need to let their children go to school. And also to tell girls who want to go to school to come personally to register with the education authorities." (Non participating woman, women's group treasurer, age 30 .)

It should be noted that one of the intended effects of the programme was to increase the demand for basic services, a demand the NGO cannot always meet. Many populations made requests of Tostan to improve their environment ranging from hulling equipment to mills, well sinking equipment, and toilets. For example, the following request was made of Tostan by the village of Soudiane: "We were organising 'gamous' religious vigils on Sunday night, and the guests arrived early on Saturday. When someone wanted to go to the toilet, he had to go in the bush. Sometimes immodest people just squatted down in front of everyone. We thought that was not good. When Tostan came and asked us what we wanted, our first complaint was no toilets; we wanted someone to build toilets. Now that we have toilets, there are no more problems. When people come, you make sure they are clean and you leave a kettle full of water." (Participating woman.) 
This is one illustration of the villages' strong desire to apply the knowledge gained from the Tostan programme. But a lack of infrastructure and human resources in some villages stands in the way of putting the knowledge into practice. One interviewee in Medina Cherif also said: “... The health hut is no longer operating due to the lack of qualified personnel, because I was the only one working there and I could not meet all of the healthcare needs of the people. Now the health hut is only there to treat headaches, wounds and give injections." (Participating woman, GAW member, TBA, married, age 40.)

One of the objectives of the qualitative portion of the study was "to determine whether the programme helped the villages form organised social groups for the betterment of the community" and "to describe the composition of these groups." The assessment was unable to find any functioning committees, other than those dealing with hygiene. According to respondents, this was not due to a lack of organisation or desire to form them, but to the lack of need for them, due to a collective resolve to honour the commitments made with respect to abandoning this "aada." (cutting). According to one participating woman, "There is no watchdog committee in the village, because we didn't find it necessary to form one, especially since we are convinced that everyone wants to abandon these practices that are considered harmful to the health and well-being of our people. Today every part of the community, in every social, ethnic or other group, agrees that we need to abandon these harmful practices no matter what."

In conclusion, most of the women interviewed gained new knowledge from the programme and greater mastery over health and hygiene issues. We do not know to what extent the programme affected the knowledge and practices of all of the women in the villages, but there is now a core group of women with new knowledge in these villages. The programme also increased women's confidence in their own abilities and gave them leadership aspirations. Knowledge acquired in health and hygiene came to the forefront immediately. Knowledge in mathematics and literacy were also said to have increased women's management skills. These behaviours affected even some women who had not attended classes, but who live in the village and are part of the movement to improve health and hygiene.

However, in some villages the programme was not fully implemented and did not achieve its objectives. Two of the villages visited had encountered problems that prevented the women from acquiring as much knowledge as in the other villages.

It should be noted that the lack of basic infrastructures in the villages is preventing the populations from making full use of their new capacities. A shortage of drinking water, latrines, health huts and healthcare personnel stand in the way of actual implementation of the theoretical behaviours learnt in the programme. This is illustrated by the villages' demand for basic infrastructure, which was requested of an NGO whose mission is to provide knowledge and promote healthy behaviours. In a few isolated cases, Tostan was able to meet these requests through additional financing, but this was rare. Lack of follow-up from Tostan also limits application of the knowledge acquired, resulting in some missed opportunities. With the exception of the village hygiene groups, the committees that were formed during programme implementation no longer seem to be functioning, and so community actions for building a better environment have slowed down. 


\section{Public DeClarations}

Within the study areas, public declarations were held only in the villages of Medina Cherif, Malicounda Bambara and Diabougou. In the framework of the Tostan programme, these declarations arose as the natural outcome of the capacity-building process. The declarations were solemn occasions at which the communities publicly renounced all forms of practices deemed harmful, in particular FGM/C and early marriage.

\section{Initiation of public declarations and adherence to the mobilisation process}

In general, public declarations are presented by Tostan as the logical outcome of a process of increasing awareness about the disadvantages and harmful effects of FGM/C, on the part of women participating in literacy classes and thereby receiving instruction concerning their rights and reproductive health. The data show that this strategy was initially suggested by Tostan and later acted upon by the women of the Malicounda class. "One day Tostan came here and said, 'you should organise a programme.' We said, 'what programme?' Tostan answered, 'you should tell the whole village what you are learning. We could invite important people and journalists here for discussions." "(Participating woman.) After this, dialogues were initiated by the women in the Tostan class. "Everyone knew about it. We told the important people in the village and they agreed; we told the imam and he agreed; the same with the village chief. We were at the home of the village chief; he came to our class himself. When we performed the play, he saw it, so it is obvious we did not take this decision on our own. (GAW president).

Another key informant also underscored the extensive dialogues with village leaders, including religious leaders: "So when we talked with the village chief, he gave us to understand that we are natives of this village and he could not oppose an initiative that promoted health. Then we went to see the imam to ask if it [abandoning FGM/C] would compromise our religious practice, and he gave us to understand that it would not compromise our religious practice in any way. The problem is that we could not meet with everyone in the village." (Participating woman, age 44.)

The public declaration of Malicounda Bambara was made by the class, not the village, which is probably why the women subsequently encountered enormous difficulties in terms of criticism, opposition, threats, and insults, according the women's statements. Information provided shows that the women had not intended to generate such publicity for their actions. The problem was "that the journalists interpreted our words incorrectly and added things we had not said. Everyone pulled back, no one supported us anymore. The people said all kinds of things that weren't true: 'Bambara women have sold out. If they have decided to abandon this practice, it is because someone paid them to.' But none of that was true. We had not been given any money [visible distress]. It is only because we learned about our rights and women's health that all of this started and we decided to abandon FGM/C." (GAW vice-president.)

Some informants, including some participating women closely involved with the event, also felt the women had been "duped" by Tostan, which was criticised for having disappeared after it got what it wanted. The women felt they were not rewarded enough for what they had dared to do, for the first time, in Senegal. And it is for this reason that some informants say they could not 
continue to be active on the FGM/C committee, because it demanded too much time and took them away from their families, while they got nothing in return for it from Tostan.

Respondents indicated that Tostan played an important role in the organisation of the public declarations of Malicounda and a particular village leader from Keur Simbara was important in the case of Diabougou. The public declaration of Diabougou was influenced by Malicounda's stance on FGM/C and the holding of the public declaration itself. The leader from Keur Simbara was initially against abandoning FGM/C at Malicounda, but Tostan asked him to return home to discuss the consequences of FGM/C with relatives in his village. He came back two weeks later with a different perspective and was ready to promote abandonment of FGM/C. The importance of the village of Keur Simbara cannot be measured in terms of its population or geographical area, but by its influence on surrounding areas through historical, emotional, cultural and social ties. A leader in Keur Simbara explained to us the process by which other villages came to adhere to the principle of abandonment as a necessity to avoid marginalisation: "... Because for us, the place where we marry, that is our village. Our village actually consists of ten other villages, because that's where our daughters marry. And our sons take their women for wives. So if we abandon the practice, where are they going to find women? We will be rejected and marginalised!”

Numerous discussions took place in villages affiliated with Keur Simbara - including Diabougou where the public declaration was eventually held - over the idea of participating in a public declaration. The women of Malicounda visited the women of Keur Simbara at the request of a village leader. "D. came and asked us to come to his village... He asked us to go there because they had received the education program but had not dared to speak the words "abandon $F G M / C$.' He told us to come and raise awareness in his village." (GAW president.) These negotiations sometimes generated great discord in the villages. This was the case in Diabougou, where those attending the discussions actually came to blows. According to the president of the women's group: "When D. came to ask us that, at first we refused because we were told it meant giving up our custom ... and people were negotiating to accept that. ... We were born and grew up with this custom; our older daughters had gone through it with no problems. All of a sudden, Tostan comes and tells us 'stop it.' This created a lot of disturbance. And I was one of the ones who was deeply opposed to abandoning it." (Women's group president, married, age 44).

In the end, the knowledge acquired in the classes, the sheer persistence by some individuals, and the visits and discussions with the women of Malicounda overcame the resistance. "There are difficulties with it [FGM/C]. It's true we inherited it from our ancestors, but through what we learned we saw that there were difficulties" (Women's group president). This same respondent underscored the involvement of parents in the decision-making process to abandon FGM/C: "We discussed it with the parents, those of us who had attended the Tostan class. We showed them the difficulties it caused. They had not learned about it, but we told them about the difficulties and so we were able to participate in the Declaration of Diabougou."

By the time of the public declaration in Medina Cherif, the third such declaration, the process had already evolved. Numerous parties in the villages were involved to pave the way for holding a public declaration and mobilising the population to abandon FGM/C. "It came about thanks to the determination of certain people, but also to what we learned in the training, and finally, to the importance of the Tostan programme to us. The people themselves took the initiative; they 
thought we needed to hold a meeting where everyone involved could exchange views. That is how we came to tell Tostan about the situation, and they responded favourably and asked us to include other villages, if possible, so they could participate in the meeting by sending delegates to Medina Cherif, something we gladly agreed to do. And that is how Tostan decided to pay all of the expenses of this meeting." (Participating woman, women's group member, married, age 40).

Even villages that were somewhat critical of the programme ended up rallying around the public declaration. But there was no vocal opposition during the declaration itself, as indicated by one facilitator: "... There was no opposition from the people in the village; even imam F.S., whom we had contacted, was in favour of the declaration."

For both Diabougou and Medina Cherif, the process of adhering to a public declaration occurred in several stages, mainly as the result of a consensus on the part of village leaders. However, the people were also closely involved. "It was a spontaneous decision. It was not made by the village chief alone. There was a consensus among the village leaders, who decided to participate in the public declaration after dialogues with the village." (Participating woman, women's group vice president / treasurer, age 40.) But this consensus was achieved only after long negotiations, described by a facilitator in this way: "Frankly, the discussions were contentious and went on for hours before a consensus was reached in the village, because some people found it hard to come to terms with the situation."

The involvement of religious leaders also helped smooth over some differences. According to one facilitator: "Those who attended had different points of view. Some were for, others against but did not say so publicly for fear of being attacked by the abolitionists. But the religious leaders told those present that Islam was not opposed to abandoning traditional practices deemed harmful to the people's health. After these explanations, the people agreed to adopt this declaration."

\section{Participation in public declarations by villages that did not receive the programme}

The Tostan programme was also influential in persuading other villages to adhere to the public declaration process. In the Kolda region, as in Thiès / Fatick, participation in public declarations by villages that had not received the education programme often came about through family or marital ties. Most of the villages attended the declaration out of a feeling of support and solidarity, or out of curiosity about festivities being held in another village. Their participation in the declaration rarely sprang from a process of internal awareness and informed decision. In some cases the invitation to attend arrived only a few days prior to the event, or even the night before, according to some respondents. The villages of Nema Counda and Mballo Counda, the only type B villages visited, indicated that they had not even been invited, but had simply heard that festivities were going to be held. "I saw people leaving from Saré Waly, Saré Samba Woury to go there. So I asked the other women in my village to go with me to see what was happening in Saré Hogo. Some women categorically refused, telling me they had no business there because they had not been invited. I told them no, we're going, because I am from Saré Hogo and I don't 
need an invitation like everyone else. We're going to find out what they are talking about at this gathering." (Woman from Saré Hogo). Thus, associated villages attended the public declaration without really knowing what was at stake. Attendees from these participating villages realized only after their arrival that the purpose of the "festivities" was to abandon FGM/C.

Some villages were driven to attend mainly out of curiosity. Such was the impression of a participating woman from Saré Ansou: "I cannot say that everyone who attended unanimously agreed with the cause, because in this huge crowd some were there simply out of curiosity. ... What I can say is that in our village we practice FGM/C and we have never had any problems with this practice." (Participating woman).

In some instances, villages participated in a public declaration simply to follow the lead of other organising villages. The idea behind this "came from people in the area who had heard about a declaration in another area. They were aware of the importance of such an event for the people, so they thought they should organise a declaration for their own benefit." (Facilitator, shopkeeper, married, age 38). Apart from being a big event, the public declaration was seen as a way of attracting numerous advantages to the village: "The advantage of this declaration to the people is enormous. This declaration in favour of abandoning these practices improves health and hygiene conditions, if for no other reason than that the people will now be able to combat some of the illnesses raging among the population, sometimes even without the help of a health expert." (Facilitator).

In some cases participation triggered a process of reflection. The village of Soudiane, for example, did not agree to abandon FGM/C when it participated in the first public declaration. According to a facilitator, it was only after returning from the public declaration that some in the village decided to abandon FGM/C: "After we came back from Diabougou, everyone who had gone said, 'From this day on, I will abandon FGM/C because what I heard today convinced me.' The village chief told them, 'I don't require anyone to abandon it; if you want to abandon it, that is fine. But once you have said you are going to abandon it, you cannot go back. Abandon it if you will, and if you cannot, you are free to continue your custom. Have you decided to abandon it?' And the people said, "Yes, we are abandoning this custom."' It was the people themselves who decided to abandon the practice of their volition.

The example of Nema Counda is an instructive one. According to the village imam: "FGM/C has been banished by the people of this village. Tostan conducted awareness-raising activities with discussions about FGM/C to teach people the harmful effects of this practice. Our village heard about all of these activities and attended several meetings about FGM/C in Medina Cherif. That is what motivated us to participate in the public declaration".

\section{Designation of village representatives to attend the declaration}

According to some sources, the selection of village representatives to attend the public declaration was based on suggestions from Tostan, which stressed the participation of resource persons. As mentioned earlier, marital ties between the presidents of the women's groups of the villages where the programme was implemented and another village, or other familial ties, were the basis of the selection of resource persons. In principle, these representatives were proxies 
sent to speak on behalf of their respective communities, as explained by a woman from Keur Simbara: "Those who attended did not go there on their own behalf, but to represent the village 'kaddu deukke gui la gnou yobou.'” (Women's group president, married, age 50).

In this way, information was conveyed back to the villages. "... When they came back, the representatives reported to the people and explained the purpose of this declaration and the consequences of such practices for our health and exhorted them to abandon FGM/C and early marriage for our social well-being. " (Facilitator, married, age 38).

However, according to accounts from type B villages, participants did not always go as part of an official delegation. Some women simply decided to attend the festivities in a neighbouring village. "I cannot say they were sent by the village, due to the simple fact that the representatives didn't even know what was going to happen at this gathering or what they were going to talk about. All they knew was that A. was going to receive distinguished guests and there would be a big party that they didn't want to miss under any circumstances. ' (Woman, age 35).

\section{Measures adopted in conjunction with the public declaration}

After the public declaration, measures were taken to support the collective decisions made in conjunction with the event. The measures related mainly to monitoring the abandonment of FGM/C and establishing strategies to address other problems in the villages. This was the case with malaria, against which "commitments were made to install pharmaceutical tables where people could buy anti-malarial drugs during the rainy season, because getting to the health posts is very difficult." (Facilitator, married, age 38).

With respect to the practice of FGM/C, a number of measures were adopted to support adherence to the public commitment. These varied from one village to another, but most had to do with putting an end to the practice and monitoring it in the communities. In this regard, the Goundaga facilitator remarked: "The first thing we asked them was if they were sure they could honour this decision to abandon the practice, because it was something they had affirmed in public. In particular, we asked them to keep an eye on the circumciser because some people might be tempted to go see her in secret. I told them from the outset that they needed to create a committee for this [watchdog committee]." (Facilitator, married, age 44).

However, because the initiative to abandon FGM/C had been taken collectively, the people held themselves responsible for adhering to it. Thus, the treasurer of the Goundaga women's group created tasks that have since been carried out by the village chief: "After the people decided to abandon these practices at the village meeting, the village chief told them that he had a moral obligation to enforce these decisions and that he would not hesitate to prosecute anyone who practiced FGM/C or early marriage in the village".

The facilitator in Soudiane explained the measures adopted by this village in this way: “... The people said 'since you are the ones who decided to abandon this practice, no one forced you, anyone who violates the decision will be taken to court,' and everyone accepted this warning. " (Facilitator, married, age 46). 


\section{Enforcement of measures and community monitoring}

Extensive negotiations preceded the organisation of public declarations and it was crucial for those who had already held a declaration to share their experiences with others. Knowledge acquired in the classes was used to bolster arguments. Because some were convinced more readily than others, public declarations did not follow immediately after implementation of the programme. A period of reflection and dialogue was necessary to build on the process. Other villages became involved through family and marital ties, but not necessarily as the result of a pre-planned strategy. Some villages attended by chance or out of curiosity. Only a few leaders from a village attended the event at the organising village; the rest of the population was generally unaware of the implications of the event and thought it was a party. So there was often an absence of mobilisation activities around the pertinent issues in the associated villages. Even the leaders themselves often attended simply as observers, and it was only upon their return that negotiations were instigated within their own communities.

Enforcement of the measures announced at the public declaration required the contribution of several social groups in a village (e.g. women, leaders, young people). Respondents indicate that it was the collective determination on the part of the communities to honour their commitments, along with the support of leaders, committees and especially women, that determined the effectiveness of a declaration.

In general, the motivation for adhering to these measures sprang mainly from dialogues in the villages, where "one's word is one's bond," obligating a community to respect the decisions it had made. The honour of the people was at stake if a pledge made in the public's eye was broken. The president of the Diabougou women's group spoke of the value of these commitments: "I simply say to myself that when an 'ass gorr' [honourable person] stands before everyone and declares that she has abandoned FGM/C, she must keep her word... 'kaddu gogou gnou wax, mo gnou ci rey' [it is our word that unites us]. We would be really ashamed if people said, 'Diabougou declared that it was abandoning FGM/C, but people are still doing it.",

One village chief indicated the importance of the decision to abandon FGM/C in his community as follows: "For FGM/C, there were long dialogues organised mainly by the women themselves. We all agreed to abandon this custom, which has nothing to do with Islam. The world was our witness when we made this commitment. It is beyond us, but we would never have agreed to it if we had not been convinced of the rightness of the cause, and if we were not determined to follow through with it." (Village chief, married, age 96.) The commitment of men should also be noted. "The men never refused to abandon FGM/C, because if they were against it, the public declaration would not take place. If it is still in place it is because they are still in agreement," one imam told us.

The public declaration also conferred recognition on the organising villages, which felt they had made a name for themselves by hosting an event of this magnitude, as illustrated by the remarks of a school principal: "First of all, it was an honour. Medina Cherif held the public declaration, and it was a very good thing for the village. That is how the people feel. We were honoured because Tostan came and we did something that is now known across the region. In fact, not only the region, but the world, everywhere, because whenever one speaks of Medina Cherif in Kolda, it will be well received by the people." The idea is that the decision will hold over time 
and that monitoring actions are not necessary because the community decided to abandon FGM/C of their own volition, as stated by this imam: "You know, before, no one went into hiding over this practice, so I think they don't need to monitor it; all the more so as they decided to abandon it of their own free will."

The commitment made at the public declaration and word given by the persons that attended are seen as guarantors of the declaration's effectiveness. Not many structured watchdog committees were formed; a few awareness actions and reminders were considered enough to hold the commitment in place. Thus, even in the absence of a village watchdog committee, the communities affirm that they will honour their word. According to respondents, the law that bans the practice of FGM/C in Senegal also provides impetus for adhering to the decision.

Nevertheless, some strategies were adopted to enforce the decision. These range from communication to coercion, and include dissuasive methods on the part of informal committees, among other groups, in the villages. One facilitator told us about his village, where "... there was an informal committee, made up of the village chief, the imam and a few representatives of the group, that monitored the application of these measures and if a family was caught continuing to practice these acts, it could be punished by the committee."

However, information gathered during this study found no instances of punishment. Awarenessraising and monitoring seem to have ensured compliance, as attested by the president of the Keur Simbara women's group: “We cannot monitor any more than we already have, the leaders and myself; I am the president. We just discuss it with our members to make them aware and I know that if one of the leaders caught someone in the act, he would be sure to confront them, saying 'you must never do this again. If you do, I will tell on you and do such and such to you.' But I have yet to see the leaders have to reprimand anyone. Really, ever since we had our discussions and came to an agreement, our commitment has held firm..." (Women's group president.)

The public declarations also seem to have generated positive changes. According to one school principal, these changes relate to "a shift in attitudes since the public declaration," after which "women have better standing in the community, in comparison with the past. If the word 'liberated' is too strong, let's just say that the women have regained a certain dignity and play a leading role in the economic life of their society." In response to the question of how long this situation will last, this interviewee expressed his feelings as follows: "I have no fear that it won't last, because these activities are being carried out regularly and consistently."

The data show that the public declarations helped end FGM/C and other harmful practices. Its importance in the villages is illustrated by the respect shown for the decisions made, as expressed by this imam: "It [the public declaration] has great significance in this village because, as I just explained, I have not seen or heard of a single case of FGM/C in the village since then. So this practice is declining or is being totally abandoned by the population."

In conclusion, it should be noted that the first public declaration was suggested by Tostan as a way for women in the class to share their knowledge with the rest of the village. Although this first declaration was made by the Tostan class, it resulted from a dialogue process with village leaders. This first public declaration was the catalyst for all of the declarations that followed, whose significance and organisation strategies changed over time. From a declaration by a group 
of women who had participated in the programme resulting in their marginalisation, the public declaration evolved to include other members of the village, with leaders at the forefront. The actions of a particular leader in the Thiès region were probably key to this transformation.

\section{EFFECT ON EARLY MARRIAGE}

The notion of early marriage was not clearly understood in most of the study villages. Often the ideal age at which a girl should marry turned out to be very young. "A girl should have a husband between the ages of ten and twelve. She is mature enough at that age," stated a non participating woman from Néma Counda. Another woman added: "Is fifteen the age to get married? It starts at twelve or thirteen. But I was married at the age of fifteen." (Non participating woman, farmer, married, age 30). One of the interviewees said further: "If she is not yet 15 and she gets pregnant, she could end up dying. At 15 she can carry a pregnancy."

In a few villages, fifteen was considered young, and could lead to complications during pregnancy and childbirth. The Tostan programme seems to have had an impact on opinions in this regard, as indicated by a non participating woman from Medina Cherif: "Yes, we also stopped giving our daughters in marriage so soon. Before, we gave them at fifteen and the girls had complications during pregnancy and childbirth. The Tostan programme made us aware of all of these problems that young girls encounter in pregnancy." (Non participating woman).

Fear of a daughter becoming pregnant out of wedlock was often cited as justification for early marriage. However, a shift in views is taking place regarding, in particular, the right of girls to choose their own husbands and give their consent before being committed to a marriage, as explained by this school principal: "Early marriages are also due to one thing: the parents here say that if their daughters get pregnant, it is a big problem, and when they see their daughter going out a lot, they start to worry..." (School principal.)

Fear of a daughter becoming pregnant was also mentioned by a woman: "Whether you give your daughter in marriage very early or not, if you decide not to give her in marriage very early, she will be bringing you home a child. There are many here now. ... So if you see someone bringing cola nuts and wanting to marry your daughter, you will give her in marriage. If not, she will cause you another problem. ... It is because of the girls that early marriages are made, because they don 't take things seriously." (Non participating woman, women's group member, gardener). In some villages, it is believed that the risk of pregnancy is even greater after the abandonment of FGM/C, because this also means abandoning taf (formation of scar tissue closing the vagina), which is seen as the assurance of a girl's virginity.

In some villages, the programme seems to have had an impact on the awareness and monitoring of early marriage, as attested by the village chief of Saré Waly: "When you give your daughter in marriage to a man, if she does not want to go she is going to cause you real problems. It is better to wait until she grows up to marry her off or better to let her choose her husband herself."

Generally, however, the age at first marriage has remained young in the study areas, although perceptions seem to be moving toward recognising the advantages and necessity of not marrying 
girls too young or marrying them without their consent. This is said to be behind the lack of committees for monitoring the abandonment of early marriage, as indicated by the president of an association based in Medina Cherif: "At first we had this committee but now we no longer have it because now we have noticed that there are no more men giving their daughters at the age of 17, or 18. Now it is the girls who choose their husbands themselves. Now, with school, there are principals who make everyone aware of this issue." (President of association).

In conclusion, many informants are of the opinion that early marriage is declining. In both Kolda and Thiès, most informants stated that there are many disadvantages to the practice and, for this reason, it is in the populations' interest to abandon it. Tostan's influence can be seen to some degree, because of its emphasis on the consequences of pregnancy in young girls. But other influences should also be recognised, such as school attendance by girls, greater emancipation of girls as they come into contact with other cultures, awareness raised by the media, and the fear of legal sanctions.

However, it is still not clear what the populations consider to be "early." In the Kolda region in particular, anything under the age of 15 is considered early; at 15, a girl is considered mature enough to be given in marriage. The fear of pregnancy out of wedlock, and thus of family dishonour, often causes families to marry their daughters young. But early marriage has increasingly become a topic of conversation in the villages.

\section{EFFECT ON FGM/C}

The study explored the issue of FGM/C extensively through various questions, checking with key informants external to the programme, and through data triangulation. According to the data gathered, most of the men and women interviewed said that the practice is now being abandoned in the villages, with only rare incidences, or the complete absence of, new cases of FGM/C, since the public declaration. As one facilitator put it: "Since the declaration, not one case of FGM/C has been seen, although girls are being born in this village." Women from other villages support this view. "Before the public declaration, there were girls being circumcised. But since we made the public declaration, we have abandoned it because we are Bambaras. If we decide to do something, we don't go back." (Non participating woman, age 50). "We talked about FGM/C and abandoning it and finally we assigned people to monitor whether or not it was being abandoned in the village; so no one is practicing it anymore." (Non participating woman, age 37).

The decision seems to be supported as much by women who did not participate in the programme as by women who did. "Now you can't tell the difference between participating and non participating women; they all behave the same ... Our older daughters are following in our footsteps. We have stayed on this path up to the present because it was a general decision taken by the village. We abandoned it; it is no longer practiced in the village. Since the public declaration I have neither seen nor heard of anyone circumcising his daughter in the village or beyond." (Non participating woman, age 39). 
Leaders seem to have taken it upon themselves to remind people of the decision. "In each village there is a leader. From time to time this leader calls a meeting at which the people are reminded of the consequences of the practice. Really I see that it has been abandoned." (Non participating woman, widow, age 55).

However, doubts persist, as expressed by the imam of one village: "Ah, in any case, we were doing it but now we are not doing it anymore. Because, before, it was a big ceremony, there was a big party, we sang and danced. It was organised within the traditional village association. But now someone could be doing it at home and no one would know. I don't know if it has really been abandoned, but it is not organised like it was before." (Imam, age 78).

One older woman expressed the feeling that "people will give up FGM/C, but it will take a long time." (Women's group president, widow, age 67.) Another elderly woman pointed out that she no longer has any daughters of circumcision age, but she is not convinced: "With regard to $F G M / C$, the thing is, I have no more girls at the age of circumcision. But if I did, it would be a problem. It would be difficult for me to abandon the practice. I admit it." (Non participating woman).

A few people said they had heard that some form of incentive was given to facilitate the abandonment of FGM/C. It seems that some of Tostan's actions were interpreted as privileges accorded to certain villages, which created jealousy. This is illustrated by the comments of the president of a sports and cultural association: "They said they abandoned it, and since then I have not seen a woman circumcise her daughter with my own eyes ... because I heard that Tostan gave the women's group a machine to learn how to sew ... It is also said that Tostan offers hard cash for abandoning it ... It went all the way to the National Assembly and told them we abandoned it and received money. But until this time, as I am talking to you, I have not yet seen the colour of that money!

Some respondents in a type B village doubted that FGM/C had been completely abandoned by everyone. However, these informants affirm that, at the very least, the practice has changed. "It is difficult to find anyone who is circumcised or to hear about someone being circumcised. It continues; there are people who circumcise their daughters in secret." (Village chief).

However, such doubts and convictions regarding continued resistance were expressed by only a very few. Most respondents maintained that the practice has been abandoned and that the commitment not to return to it is still strong. This was true for all of the villages that participated in the process. "The only effect the public declaration has had, as far as we can see, is that it sealed the fate of FGM/C in our village, where it no longer exists." (Imam). In addition, a girl's status with respect to FGM/C does not appear to impede her 'marriageability'. According to one facilitator, the initial distrust is now over: "At first, some men were somewhat suspicious of these girls, but for some time now they have realized that these non circumcised girls are cleaner and healthier than the circumcised girls. Since then they have a great deal of respect for them. Which means that today they have no problems finding suitors". This was also confirmed by the women. "There are many non circumcised girls in the village. They are well regarded. They are not excluded socially at all for anything having to do with FGM/C. I think that people are more or less aware of the danger of these practices for people's health and their children's future." (Non participating woman, farmer, age 42). 
Nevertheless, there are still a few resistors who say they will never abandon the practice. It is difficult to develop a consistent profile of these resistors. In one village, it is an elderly woman, in another a youth leader who supports FGM/C.

Some resentment was expressed by the pioneers of abandonment, however, who feel they were not sufficiently rewarded for having had the courage to oppose this age-old practice.

In conclusion, in all cases, whether the initiative to abandon was taken by participating women, alone or in agreement with village leaders, or by the population as a whole; and whether or not the decision was supported by Tostan, the abandonment of FGM/C is a reality confirmed by the majority of the people in the villages surveyed.

There is, however, a slight difference between the Kolda region and the Thiès/Fatick region. Accounts from Thiès and Fatick indicate that almost everybody agreed on the abandonment, while in Kolda it was reported lower. However, if FGM/C is still being practiced, it is no longer visible.

\section{DISCUSSION AND CONCLUSION}

The Tostan programme has clearly had a real impact on the life of villages and individuals according to the key informants. However, the study team is aware that respondents may have misrepresented certain facts, despite being constantly reminded that the study was being conducted not by Tostan but by an independent research team. In this regard, certain questions are raised by the evaluation.

\section{Questions raised}

The first question relates to the village selection process. All of the information gathered from both Tostan and community members indicate that certain conditions were necessary. Villages with strong leaders and the ability to support a facilitator are both factors that affected village selection. After the first public declaration, the name of Tostan became synonymous with abandoning FGM/C, as the event was widely covered by the media. A transition was also seen as villages began requesting the programme through the influence of inter-village migrations and the programme's popularity. For this reason, the possibility of selection bias should be considered. If an agreement to abandon FGM/C appears to be a condition for introducing the programme into a village, the most resistant villages will naturally exclude themselves from the selection process. The most destitute villages may also be excluded because they are unable to support a facilitator.

It should also be recognized that Tostan's strategy of requiring the village to contribute resources more or less constitutes a pledge of ownership. The community plays a major role in introducing and implementing the programme, and participates fully in the activities. Once they have undergone the process of negotiation, the level of programme acceptance is very high. The effort made by villages to provide classrooms and accommodation for facilitators, even if they are very poor, more or less guarantees their participation in the education programme. 
Other questions may be raised concerning the participants themselves. Inconsistent attendance and dropouts over time may also result in bias. Even if the reasons were justified, only the most motivated women participated in the complete programme. Does this mean that only the most determined women, who probably have the most progressive ideas, benefit fully from the program? In other words, do only the most convinced, those already predisposed to change, end up building their capacities? A previous evaluation has already shown a higher level of knowledge among these women before the programme began (Diop et al. 2004). The less independent and perhaps busiest women with household chores and children (and therefore usually the youngest women) end up being less involved. However, one interesting result of the study is that any differences between participants and non participants tends to be erased over time, with other women living in the village eventually reporting that they have adopted the movement toward change.

Another question we may ask is why the public declaration focused on FGM/C abandonment, even though there were a wide range of components of the programme? FGM/C is only one small section of the curriculum. Several other harmful practices were addressed in the curriculum and several other good practices need to be promoted that really impact on maternal and child mortality. Here we can see some probable influence by Tostan towards the abandonment of this particular harmful practice.

Another issue that could be raised is that of the usefulness of an education programme in a context of extreme poverty. Tostan makes a great investment in increasing knowledge and encouraging healthy behaviours that are, in the end, difficult to put into practice in areas where water, health and social infrastructures, along with qualified health personnel, are lacking. The difficulties of daily survival limit the programme's impact. Some respondents made a point of saying that the knowledge acquired is good, but has no benefit for daily survival. In this phase of the programme, it should also be noted that the classes were reserved entirely for women.

The programme's impact on early marriage is less apparent than its impact on FGM/C, for the following reasons: 1) a number of interventions and external influences are impacting this issue (school attendance, law, media exposure, outside cultural models); 2) the sessions on marriage and women's rights were not systematically structured during this phase of the programme; and 3) families still fear their daughters will become pregnant out of wedlock.

A paradigm shift is taking place. Becoming pregnant out of wedlock is now considered more shameful, and results in greater marginalisation, than a lack of excision. However, noncircumcised girls are being associated with looser morals, due to the lack of traditional education about behaviour that once accompanied FGM/C. For this reason, the absence of circumcision is now viewed as less of an obstacle to marriage, but more of an obstacle to avoiding pregnancy out of wedlock. This is a real problem for parents, and solutions must be sought.

The programme's impact on ending FGM/C, as reported by informants is high, and was recognised by different categories of informants. Although not everyone was convinced of the need to abandon FGM/C, such voices were a minority. The process of dialogue, awarenessraising, and negotiation prior to organising a public declaration fostered a firm belief in the need to abandon the practice and ensured the declaration's lasting impact. However, a few frustrations remained over the fact that the "pioneers" were not sufficiently recognised. The reasoning 
expressed by various categories of respondents, especially women, can be summarized as follows: we were asked to abandon a centuries-old custom; we did it, even though we never saw all of the disadvantages of it that were talked about so much; therefore, we should receive something in return to compensate for this great loss of a cultural marker of ethnic and cultural identity. This resentment is still keenly felt years after the programme in these pioneer villages, which expected more of a positive impact on their daily lives. Therefore it is important to note that the health or human rights benefits that the community gained in abandoning FGM/C do not balance the loss of this traditional norm.

Resentment is even stronger in villages that feel slighted with respect to the material and financial investments Tostan made in other villages. The respondents said that although everyone abandoned the practice, Tostan seems to have favoured some villages over others. They saw more of an economic investment in other villages. This probably relates to grants that Tostan obtained from donors for economic support activities. Ignorance among the communities concerning these activities has led to frustration, and even attempts at "blackmail" regarding the abandonment of FGM/C. This "blackmail", about going back to the practice of FGM/C if nothing is done, was expressed verbally but it is difficult to know whether it has been translated into action.

Villages that attended a public declaration before participating in the programme partook mainly as observers. It was only upon returning from these events that dialogues began, as evidenced in part by the fact that these villages subsequently requested the Tostan programme for themselves. Thus participation in public declarations by non-programme villages is the start, not the end, of the process for these villages. This explains why all of the villages in the study areas ultimately received the programme. Also, although an important dialogue process takes place in these villages after attending a public declaration, it is still vital to reinforce their decision by introducing the education programme.

Over time, the communities seem to have formed the impression that Tostan is synonymous with "financing" or "projects" for women or whole villages. In fact, many people attended the public declarations (including distinguished guests, according to respondents) and the organising village received financial aid to hold it. Although such aid is nominal, it should not be overlooked in such areas with extreme poverty. In addition, although not given during the education programme itself, Tostan is generally able to obtain grants / loans for groups who participated in the programme. All of this can lead to envy and jealousy on the part of villages that did not participate in the programme.

The question of whether structural interventions should accompany or follow these capacitybuilding interventions is an extremely important one. The problem is that this is not necessarily the role or expertise of an NGO such as Tostan. But it appears necessary to seek partnerships with other programmes possessing such capacities. 


\section{Conclusions and recommendations}

All of the information collected show that the programme resulted in the acquisition of knowledge by the villages, as evidenced by changes at both the social and personal levels, but also, and especially, with respect to the perception and practice of FGM/C. The analysis focused on the social effects of the programme, shifts in health habits, and changes operating at the individual and family levels. The programme fostered improved social relations. According to respondents, women's standing improved in the villages. Moreover, a kind of synergy developed, which translated into a sort of mutual assistance in the villages whereby the problem of one village resident became the problem of all.

In terms of interpersonal and social relations, positive changes were seen in relationships and perceptions. The Tostan programme fostered better social communication in the villages. According to leaders and participating women, it contributed to improved marital relations, as evidenced by reduced conflict between spouses. The programme inculcated a culture of nonviolence in the study communities and gave them a model for solving problems, the outcome of which was improved gender relations, with the strengthening of community ties, particularly inter-ethnic relations.

Social groups were formed in the villages prior to implementation of the programme. In some places, public declarations seem to have been instrumental in bolstering these committees to follow through with the measures and decisions made. However, years later, these groups / committees no longer exist. In the villages, more or less the same people talking about the decisions are also in charge of carrying out all of the related duties, be they concerned with health, hygiene, FGM/C awareness, and follow-up and monitoring. The failure to assign specific tasks to specific members made it difficult to track the results of all of the interventions in the villages over time. This is why it is difficult to cite specific achievements or determine the positive changes as a result of these groups' leadership.

A striking change can be seen in the villages with respect to perceptions of FGM/C. In this regard, the Tostan programme clearly mobilised communities, which continue to be united around the need to abandon practices previously justified by custom or tradition and now viewed as obsolete due to the communities' new awareness. The majority of respondents stated that FGM/C is no longer practised in their village, although it is possible that the practice could be continuing secretly, particularly in the Kolda region. The situation with respect to early marriage remains more ambiguous, because the populations do not agree on the importance of abandoning this practice.

In terms of coordination and monitoring the process of FGM/C abandonment, profiles vary from village to village. This evaluation did not find any such committees in existence. However, leaders were identified as being responsible for maintaining forward momentum, both in Thiès/Fatick and Kolda. Leaders play an extremely important role in implementing the Tostan programme and, even more in the organisation of public declarations. Their opinion of the programme is very positive. However, attitudes and behaviours in the village communities sometimes indicated confusion regarding the duties and responsibilities of these leaders.

Be that as it may, the programme appears to have generated positive change at both the microand macro-societal levels. These communities now reported that they know about the harm 
caused by certain practices. But significant obstacles stand in the way of the full application of the knowledge they acquired from the programme. The lack of basic infrastructure and services blocks numerous initiatives that could result in the changes sought by the programme and in more public declarations. The study communities face enormous difficulties accessing basic social services, including:

- Water collection. All of these rural populations must travel many kilometres, sometimes by foot, to gain access to tap water; many no longer even remember the time when the boreholes functioned with wells that have since gone dry.

- The lack of health infrastructure in these areas. There are not even health huts to meet occasional requests for primary care services.

- Inability to carry out the girls' education policy, due to lack of infrastructure.

These factors constitute obstacles to applying the knowledge acquired through the programme; the lack of follow-up in the field poses as large an obstacle as the absence of support mechanisms. Tostan initiated follow-up strategies with the creation of committees, but these committees did not function as expected; the communities themselves have difficulty identifying them, or knowing what their purposes, interests, actions and accomplishments are. Nevertheless, the programme achieved significant results: knowledge of life skills resulting in positive changes and a shift in the perception of FGM/C moving everyone toward abandonment of this practice.

Two main recommendations emerged from this retrospective assessment:

1) There is a need to provide support to these villages following the public declaration. For most of the population within the village, the public declaration is the beginning of a questioning process. While leaders play a strong role at the beginning and during implementation of the education programme, including the initiation of the public declaration, the rest of the population is not fully participating. A mechanism of follow up will enable more actions from the leaders to sustain the decision within the village.

2) There is a need to provide more support to families/communities that have abandoned the practice. There are a growing number of girls that are reaching the age of adolescence. The influence of modern society is impacting the behaviour of young people, even at village level. Unfortunately some parents attributed these behaviour changes to the lack of education, including circumcision. Good life skills education programs may reduce this growing concern of adults. 


\section{REFERENCES}

Diop et al. 2004. Evaluation of a community-based programme in Senegal. Population Council Frontiers in Reproductive Health, Population Council: Dakar Senegal.

Ministry of Health and Medical Prevention. 2005. Senegal Health Report, MOH: Dakar, Senegal.

Ministry of Health and Medical Prevention. 2005. Demographic and Health Survey of Senegal. Human Development Research Centre, ORC Macro.

Republic of Senegal, Ministry of the Economy and Finances, Department of Forecasting and Statistics, Regional Service of Fatick. 2005. Economic and Social Situation of the Fatick Region.

TOSTAN. 1999. Breakthrough in Senegal. Ending Female Genital Cutting, Population Council: Dakar, Senegal. 